\title{
Ensinar pelas séries: atipycal e a problemática do transtorno do espectro do autismo (TEA)
}

\section{Ensinar pelas series: atipycal e a problemática do transtorno do espectro do autismo}

\author{
Solange Rocha da Silva; GiUSlane Francisca da Silva
}

\section{Resumo}

Pensar como o seriado Atipycal pode ser utilizado como um recurso pedagógico, é o objetivo desse artigo. Para tanto, exploramos alguns aspectos das três temporadas de Atipycal, seriado produzido pela Netflix. Atipycal aborda de uma forma descontraída as dificuldades e desafios enfrentados por Sam, um adolescente dentro do espectro autista, em grau leve. Ao problematizar as relações familiares e as dificuldades encontradas pela família Gardner para lidar com Sam, a série também evidencia a importância do engajamento da família para o desenvolvimento de uma pessoa dentro do espectro. Dessa forma, o seriado é um importante mecanismo que possibilita ao público conhecer e refletir sobre as condições de vida e a inclusão escolar e social de uma pessoa autista. Assim, a série pode ser utilizada como um recurso pedagógico em sala de aula, pois, Atypical nos possibilita refletir sobre como a escola tem lidado com as diferenças.

Palavras-chave: Seriado; TEA; Dimensão educativa.

Teaching trought series: Atipycal and Autism Spectrum Disorder (ASD)

Abstract: Reflecting on how the TV serie Atipycal can be used as a pedagogical resource is the goal of this paper. Therefore, we explore some aspects of the three seasons of the TV serie Atipycal, produced by Netflix. Atipycal explores, in a humorous way, the difficulties and challenges faced by Sam, a teenager within the autistic spectrum, in a slight degree. By problematizing family relationships and the difficulties encountered by the Gardner family in dealing with Sam, the TV serie also highlights the importance of

\footnotetext{
a Universidade do Estado do Rio de Janeiro, RJ, Brasil. Doutoranda em Educação, e-mail: mariasolange@ufpi.edu.br; Universidade do Estado do Rio de Janeiro, RJ, Brasil. Doutoranda em Educação. E-mail: giuslanesilva@hotmail.com 
family engagement for the development of a person within the spectrum. Consequently, the show is an important mechanism that enables the public to know and reflect on the living conditions and the school and social inclusion of an autistic person. This means that, the Tv serie can be used as a pedagogical resource in the classroom, because Atypical enables us to reflect on how the school has dealt with differences.

Keywords: TV Serie; ASD; Educational dimension.

\section{Resumen}

El objetivo de este artículo es reflexionar sobre cómo la serie de televisión Atipycal puede usarse como recurso pedagógico. Por lo tanto, exploramos algunos aspectos de las tres temporadas de la serie de televisión Atipycal, producida por Netflix. Atipycal explora, de manera humorística, las dificultades y desafíos que enfrenta Sam, un adolescente dentro del espectro autista, en un grado leve. Al problematizar las relaciones familiares y las dificultades encontradas por la familia Gardner al tratar con Sam, la serie de televisión también destaca la importancia del compromiso familiar para el desarrollo de una persona dentro del espectro. En consecuencia, el programa es un mecanismo importante que permite al público conocer y reflexionar sobre las condiciones de vida y la inclusión escolar y social de una persona autista. Esto significa que la serie Tv se puede usar como un recurso pedagógico en el aula, porque Atípico nos permite reflexionar sobre cómo la escuela ha tratado las diferencias.

Palabras clave: series de televisión; TEA; Dimensión educativa. 


\section{Introdução}

A educação é um processo pelo qual todos os indivíduos que vivem em sociedades estão submetidos. Para além da escola, a educação acontece em diversos espaços e processos sociais. Mas, "as formas pelas quais essas instâncias interpelam os sujeitos diferem, contudo, daquelas em ação nas escolas e, consequentemente, também seus efeitos podem ser distintos" (LOURO, 2000, p. 423). É, portanto, neste sentido, que propomos a discussão deste texto, ao buscarmos compreender as séries de TV como uma dessas instâncias educativas. Assim, temos por objetivo analisar a dimensão educativa da série Atypical. Objetivamos discutir como o seriado, produzido pela Netflix, trata a questão do Espectro Autista, e de que forma o mesmo pode ser utilizado como um recurso pedagógico em sala de aula.

Diversas produções cinematográficas já se dedicaram sobre o espectro do autismo. O filme Tudo que Quero (2017), por exemplo, retrata a vida Wendy Walcott (Dakota Fanning), uma mulher de 28 anos, apaixonada pela escrita que foge de uma casa especial em que vivia, juntamente com seu cachorro, para entregar o roteiro de um Star Trek que escreveu para uma competição. Em 1993, Leonardo DiCaprio deu vida a Arnie, um adolescente dentro do espectro, em Gilbert Grape-Aprendiz de Sonhador. Interpretação que rendeu indicação ao Óscar de Melhor Ator a DiCaprio. Dustin Hoffman deu vida a Raymond em Rain Man (1999), um homem dentro do espectro com grandes habilidades matemáticas. Além de Fly Away (2011), Sei que vou te amar (2007), O garoto que podia voar (1986), Adam (2009), Código para o Inferno (1998), Farol das orcas (2016). Podemos citar, ainda, Ocean Heaven (2010), considerado pela crítica como um dos melhores filmes sobre a temática, além de muitos outros. Essas produções abordam, cada uma a sua maneira, uma questão ainda um tanto desconhecida por muitos.

\section{Produções audiovisuais como fontes de pesquisa e recursos didáticos}

A linguagem audiovisual é um recurso que facilita no processo de construção de conhecimentos. Desconsiderada, antes, como fonte ou documento, a linguagem audiovisual não era concebida como documento no qual fosse possível representar historicamente a sociedade que a produziu. No entanto, com a Nova Historiografia e a ampliação do conceito de fontes históricas, “estes documentos não só são considerados 
como fonte histórica como também podem ser utilizados amplamente por nós historiadores e por professores que buscam ferramentas para tornar mais efetivo o processo ensino-aprendizagem" (BRAGA, 2017, p. 02). Um dos primeiros historiadores a tecer reflexões teóricas acerca das possibilidades do cinema como uma fonte de pesquisa foi Marc Ferro, em meados da década de 1960 (SCHVARZMAN, 2013). Com suas reflexões, Ferro contestou o poder do historiador de determinar o que é ou não possível de historicidade.

A utilização de filmes como recursos educacionais não se constitui em novidade. Tal prática foi muito comum durante o nazismo na Alemanha. Filmes eram produzidos para "disfarçar" as atrocidades cometidas nos campos de concentração e extermínio. Outro exemplo foram os filmes subsidiados pelo Estado Soviético na Rússia socialista. As salas de aulas não estariam imunes, pois eram reconhecidas as vantagens no uso de imagens e, de forma mais eficiente, o cinema como ferramentas pedagógicas (PEREIRA, SILVA, 2014). No Brasil, a produção de filmes educativos e as discussões acerca da relação do cinema e ensino remontam às décadas de 1920 e 1930. De lá para cá o uso da linguagem cinematográfica foi, por diversas vezes, revisto. Isso ocorre porque, de início, seu uso era visto somente como uma forma de ilustrar um evento ou paisagem, não como fonte capaz de produzir reflexões (PEREIRA, SILVA, 2014).

Filmes são cada vez mais utilizados em sala de aula por professores de diversas disciplinas, tanto no ensino médio quanto no fundamental ou ainda no ensino superior, pós-graduações. Outro recurso que tem se apresentado como um recurso eficaz é o uso de seriados de TVs. Disponíveis na TV aberta ou mesmo em canais por assinatura, os seriados vêm conquistando um público cada vez mais expressivo e fiel. São produções sobre diversas temáticas e para um público bem diversificado. Dessa forma, as séries têm sido apontadas como ferramentas relevantes nas salas de aulas. Jéssica Itaiane e Bruno Leite (2018) desenvolveram uma pesquisa em sala sobre a utilização das séries Breaking Bad e The 100 para o ensino de Química. Aline Locatelli e Uliane Macuglia (2018) constataram que as séries de TV Dr. House, The Flash, The Big Bang Theory, CSI (Crime Sene Investigation), ajudam na compreensão de conceitos próprios de Química. Por sua vez, Brunna Turato Lotti Alves (2018) discute sobre a utilização de séries como uma estratégia pedagógica nas aulas de Geografia, dentre outros trabalhos. Assim, conforme assinalam Silva e Monti (2019), o cinema e/ou seriados devem ser pensados de maneira mais complexa, como objeto e fonte de análise (SILVA, MONTI, 2019). É justamente Rev. Caminhos da Educação: diálogos, culturas e diversidades, Teresina, v. 1, n. 3, p. 95-110, set./dez. 2019 
nesse sentido que propomos uma análise do seriado Atypical, com o intuito de percebermos quais as dimensões educativas do mesmo. Isto é, como o seriado aborda a questão do espectro do autismo e como pode ser um recurso relevante para entender sobre o autismo.

\section{Atypical: a série e sua dimensão educativa}

Quais seriam os principais desafios enfrentados por um adolescente dentro do espectro autista? Como ele vê e encara situações simples do cotidiano de qualquer adolescente? Quais suas reações diante de situações conflituosas e/ou tensas do dia a dia? Como se dão as relações entre uma família com um adolescente dentro do espectro? Essas são algumas das questões tratadas no seriado Atypical. A série original da Netflix foi criada e escrita por Robia Rashid. Com três temporadas, a primeira com estreia em 2017, conta com oito episódios, a segunda temporada, disponibilizada em 2018, possui dez episódios, a terceira temporada foi disponibilizada em novembro de 2019, e também conta com dez episódios. Atypical narra a vida de um adolescente de 18 anos, Sam Gardner, diagnosticado com Transtorno do Espectro Autista (TEA), com altas funcionalidades. A série enfatiza os desafios cotidianos enfrentados pelo protagonista nos diversos ambientes, especialmente no colégio, no trabalho, na universidade e suas relações familiares.

Sam é um adolescente complexo que vive ansiedades, dúvidas e medos como qualquer outro em sua idade e foi diagnosticado com TEA aos quatro anos de idade. $\mathrm{O}$ adolescente vive com seu pai (Doug), mãe (Elsa), e irmã mais nova (Casey). Uma típica família estadunidense retratada em filmes e séries, não fosse o fato de ter um integrante "atípico". Grande parte da dinâmica da família gira em torno do transtorno de Sam e foi necessário que cada integrante se adaptasse às peculiaridades do garoto. A série procura retratar o cotidiano de uma família com um integrante dentro do espectro. Elsa dedicou sua vida aos cuidados com o filho, levando-o em especialistas, também participando de sessões de terapia com mães de crianças com TEA. Buscou sempre proteger o filho de qualquer evento e situações que pudessem afetá-lo negativamente. Elsa vivia constantemente com medo de que algo de ruim estivesse acontecendo com o filho.

O pai de Sam, Doug, teve dificuldades em encarar e aceitar a condição do filho e isso o levou a se afastar da família por um tempo. Doug, assim como muitos pais, a Rev. Caminhos da Educação: diálogos, culturas e diversidades, Teresina, v. 1, n. 3, p. 95-110, set./dez. 
princípio, não conseguia entender as manifestações emocionais de seu filho, não sabia lidar com o fato de o garoto precisar de cuidados constantes. Sam cresceu próximo à mãe, quem de fato acompanhou todas as suas fases. As relações entre ele e o pai se estreitaram apenas quando suas preocupações começaram a ser compartilhadas com Doug, que começa a entender o filho, inclusive suas formas de demonstrar afeição e carinho. A partir daí, o pai de Sam passou a ser o suporte que outrora provinha de Elsa. O comportamento de Doug não foge das posturas de muitos pais na vida real. É recorrente casos de pais e demais integrantes das famílias enfrentarem sentimentos de raiva, negação e depressão (MAIA FILHO et al 2016). Casey, a irmã mais nova de Sam, o protege especialmente no ambiente escolar. Desde criança foi lhe atribuída essa função que, de certa forma, a sobrecarregava. Por outro lado, a adolescente também enfrenta seus dilemas, especialmente os relacionados à sua orientação sexual.

Como dito anteriormente, toda dinâmica da família Gardner gira em torno de Sam. Isso provocou desgastes na relação entre Doug e Elsa, haja vista que enquanto Elsa estava muito envolvida nos cuidados com Sam, que acabou "presa" no papel de mãe super- protetora, deixando sua via de lado para se dedicar ao filho. Doug, por outro lado, se recusava em aceitar a condição do filho. À medida que Sam cresce e vai se tornando cada vez mais independente, Elsa se sente dispensável, o que acentua uma crise em seu casamento. Isso a leva a se envolver em um relacionamento extraconjugal que, quando descoberto, provoca sérias crises familiares. Casey, por sua vez, se sente deslocada na família, haja vista que seus pais, especialmente Elsa, em razão do espectro, sempre deu mais atenção a Sam.

Sam conta ainda com Zahid, seu melhor e talvez único amigo, que exerce um papel significativo no processo de busca pela independência do adolescente. Esse fato demonstra a importância do estabelecimento de vínculos de amizades. Julia, a terapeuta também foi de fundamental importância para Sam, ajudando-lhe a enfrentar seus medos e desafios cotidianos.

É de suma importância que pessoas dentro do espectro autista tenham acompanhamento de um especialista desde a infância. Contudo, em muitos casos, por uma série de fatores, isso não ocorre, o que afeta negativamente o desenvolvimento da criança. Também é sabido que muitas pessoas são diagnosticadas tardiamente e que a falta de um acompanhamento adequado pode acarretar um "atraso" no processo de desenvolvimento dessa criança, adolescente ou ainda um adulto. 
A série procura refletir sobre a situação de uma família com um membro dentro do espectro. É importante relembrar que Sam se encontra no nível mais leve de comprometimento. Em casos de maior gravidade, é provável que a situação da família seja ainda mais complexa. A família de Sam sempre o apoiou e procurou proporcionar a ele um ambiente ideal, de forma que viesse atender suas necessidades. Em muitos casos, assim que a família recebe o diagnóstico, não sabe quais cuidados são necessários para que a criança e/ou adolescente tenha o desenvolvimento pessoal e intelectual. O apoio da família é imprescindível para o desenvolvimento da criança e/ou adolescente dentro do espectro do autismo.

O Manual de Diagnóstico e Estatístico de Transtornos Mentais 5. a edição (O DSM-V) (2013), estabelece que há três níveis de comprometimento das pessoas dentro do TEA. É provável que Sam se encontre no nível 1, o mais leve, o que afeta principalmente sua comunicação e interação social, bem como apresenta interesses restritos e repetitivos por alguns temas, o que é muito comum em pessoas com TEA. Geralmente possuem um ou mais temas de interesse, que os estudiosos definem como hiperfoco. No caso do Sam, seu hiperfoco são os pinguins e tudo que envolve a Antártica. $\mathrm{O}$ adolescente apresenta um grande conhecimento a respeito do referido continente. $\mathrm{O}$ DSM-V estabelece que as manifestações dos sintomas podem variar, levando-se em consideração a "idade cronológica, o nível de desenvolvimento e as condições do autismo" (PIMENTA, BARBOSA, 2018, p. 03).

É importante destacar que, embora haja comportamentos singulares entre pessoas no espectro, cada uma delas possui suas singularidades, isto é, apresentam características semelhantes, porém, não de forma idêntica. Na série, isso aparece de forma muito clara, especialmente no grupo de apoio para adolescentes autistas que Sam passa a frequentar em sua escola. Cada adolescente do grupo possui peculiaridades, medos, anseios e habilidades diferentes. Isso demonstra que é importante conhecer e respeitar as características e habilidades de cada um, sabendo que cada criança, adolescente ou mesmo adulto autista aprenderá em seu ritmo, bem como possui medos, ansiedades e etc., que podem variar de pessoa para pessoa. Assim como pode não ter habilidade para algumas atividades ou apresentar dificuldades que outras pessoas na mesma condição podem não ter.

Sam apresenta um bom rendimento escolar, especialmente em Biologia, sua disciplina preferida e suas notas estão entre as melhores da turma. Ao se formar no Rev. Caminhos da Educação: diálogos, culturas e diversidades, Teresina, v. 1, n. 3, p. 95-110, set./dez. 
colegial, obteve a terceira maior nota da turma. Contudo, não conseguiu estabelecer muitos laços de amizade durante sua trajetória escolar. Paige Hardaway, colega de turma de Sam e, posteriormente, sua namorada, se torna, com o passar dos dias, sua grande aliada. O jovem também trabalha meio período há mais de um ano em uma loja de eletroeletrônicos. Foi justamente o trabalho que o levou a conhecer e a se tornar amigo de Zahid. Outra questão importante que a série coloca em discussão é a dificuldade de pessoas autistas para se inserirem no mercado de trabalho. E, quando inseridos, os desafios cotidianos no ambiente de trabalho são muitos. Por outro lado, a série também procura evidenciar que é possível pessoas no espectro executarem tarefas, ocupar os mesmos cargos de neurotípicos, estabelecer amizades, ou seja, ter uma "vida comum".

Embora possam apresentar características que podem variar de uma pessoa para outra, indivíduos com TEA apresentam dificuldades em estabelecer relações sociais ou afetivas e "dão mostras de viver em um mundo isolado" (TENORIO, PINHEIRO, 2018, s/p). Sam (também configura como uma característica comum às pessoas com TEA), não consegue entender palavras, expressões no sentido figurado ou sarcasmo, pois sua forma de compreensão do mundo é literal. Uma pergunta feita a ele, que poderia ser respondida de forma simples e rápida, pode desencadear uma explicação longa, meticulosa e, muitas vezes, fora do contexto. É na escola que Sam, com essas características, enfrenta grande parte de seus desafios. Com frequência sofre discriminação por parte de colegas que o chamam de "anormal", "esquisito", "estranho" e etc. e, consequentemente, é isolado pelos demais.

A escola se apresenta para muitos como um ambiente desafiador. Para crianças e adolescentes dentro do TEA pode ser ainda mais tenso. Um aluno ou aluna com características, habilidades e comportamentos que "não se enquadram" no padrão instituído pelos demais colegas, o tempo de adaptação tende a ser mais prolongado e, “muitas vezes, há necessidade de receber atenção especial e individualizada dos professores" (SANTA, 2019), e cooperação por parte dos colegas.

$\mathrm{Na}$ escola, Sam é tratado como diferente pelos colegas, o que o leva a vivenciar algumas situações de bullying. A série também mostra a forma como Sam vê, sente e percebe o mundo a sua volta. Assim, Atypical nos possibilita refletir sobre "o problema pedagógico" e sobre como a escola tem lidado com as diferenças. A série nos convida a pensar e repensar a escola como um espaço de educação inclusiva, pois como bem explica Skliar (2006, p. 31), “em educação, não se trata de melhor caracterizar o que é a Rev. Caminhos da Educação: diálogos, culturas e diversidades, Teresina, v. 1, n. 3, p. 95-110, set./dez. 2019 
diversidade e quem a compõe, mas de melhor compreender como as diferenças nos constituem como humanos, como somos feitos de diferenças. E não para acabar com elas, não para domesticá-las, senão para mantê-las em seu mais inquietante e perturbador mistério".

Atypical nos convida a refletir sobre a inclusão num contexto mais amplo, e não apenas em termos de escolarização. Para além da escola, a série nos leva a pensar a nossa relação com as diferenças, que não se restringe ao autismo de Sam e ao espaço da escola. À medida que a trama vai se desenrolando é possível observar a rotina de uma família com um filho autista, os desafios enfrentados e as estratégias desenvolvidas para lidar com os problemas. Neste ponto, é importante mencionar que a série procura mostrar não apenas os conflitos de Sam e as inúmeras situações por ele vivenciadas, mas também de sua família e de todos os envolvidos no processo.

Figura 1: Sam, sentado isolado no chão da escola, enquanto observa os transeuntes. Série Atypical.

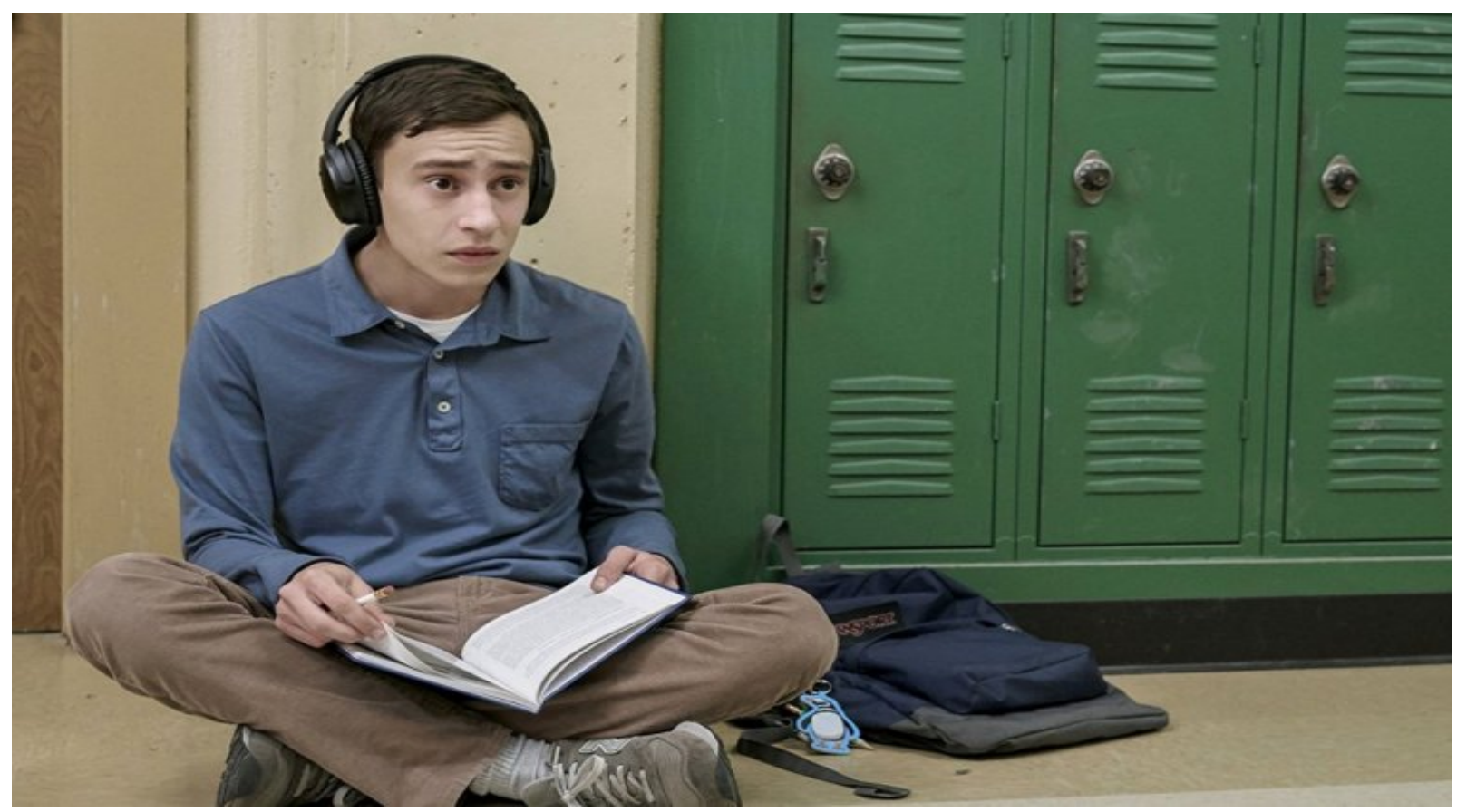

Os telespectadores de Atypical são convidados a ampliarem sua reflexão acerca das várias formas de diferenças humanas, a questionar a "normalidade" a partir das diferenças.

A diferença, sexual, de geração, de corpo, de raça, de religiosidade, de comunidade etc. envolve a todos, a todos 
nos implica e determina: tudo é diferença, todas são diferenças. E não há, deste modo, alguma coisa que não seja diferença, alguma coisa que possa deixar de ser diferença, alguma coisa que possa ser contrário, oposto das diferenças. Seria apropriado dizer aqui que as diferenças podem ser muito mais bem compreendidas como experiências de alteridade, um estar sendo múltiplo, intraduzivel $e$ imprevisivel no mundo (SKLIAR, 2006, p. 31).

Para Skliar (2006, p. 18), precisamos questionar se "há por acaso, alguma coisa que possa ser chamada, pensada e definida como normal? Existe, então, aquilo que deve continuar sendo o modelo de normalidade?".

"Normalizar" significa escolher arbitrariamente uma
identidade e fazer dela "a identidade", a única identidade
possível, a única identidade "verdadeira". É por isto que uma
educação especial "não-tradicional", se é que ela existe,
poderia ser pensada como um discurso e como uma prática
que torna problemática e inclusive insustentável - e mesmo
impossível - a idéia do "normal" corporal, do "normal" da
língua, do "normal" da aprendizagem, do "normal" da
sexualidade, do "normal" do comportamento, do "normal"
da escrita e da leitura, do "normal" da atenção, do "normal"
escolar etc. (RODRIGUES, 2006, p. 19).

E neste movimento podemos observar o viés educativo da série que mostra personagens complexos, entre eles, Sam. Por outro lado, a série também aborda a falta de conhecimento das pessoas a respeito do transtorno, o que pode acarretar em situações um tanto embaraçosas e traumáticas para a pessoa autista.

Figura 2: Cena em que Sam é abordado pelo policial Timms. Série: Atypical. 


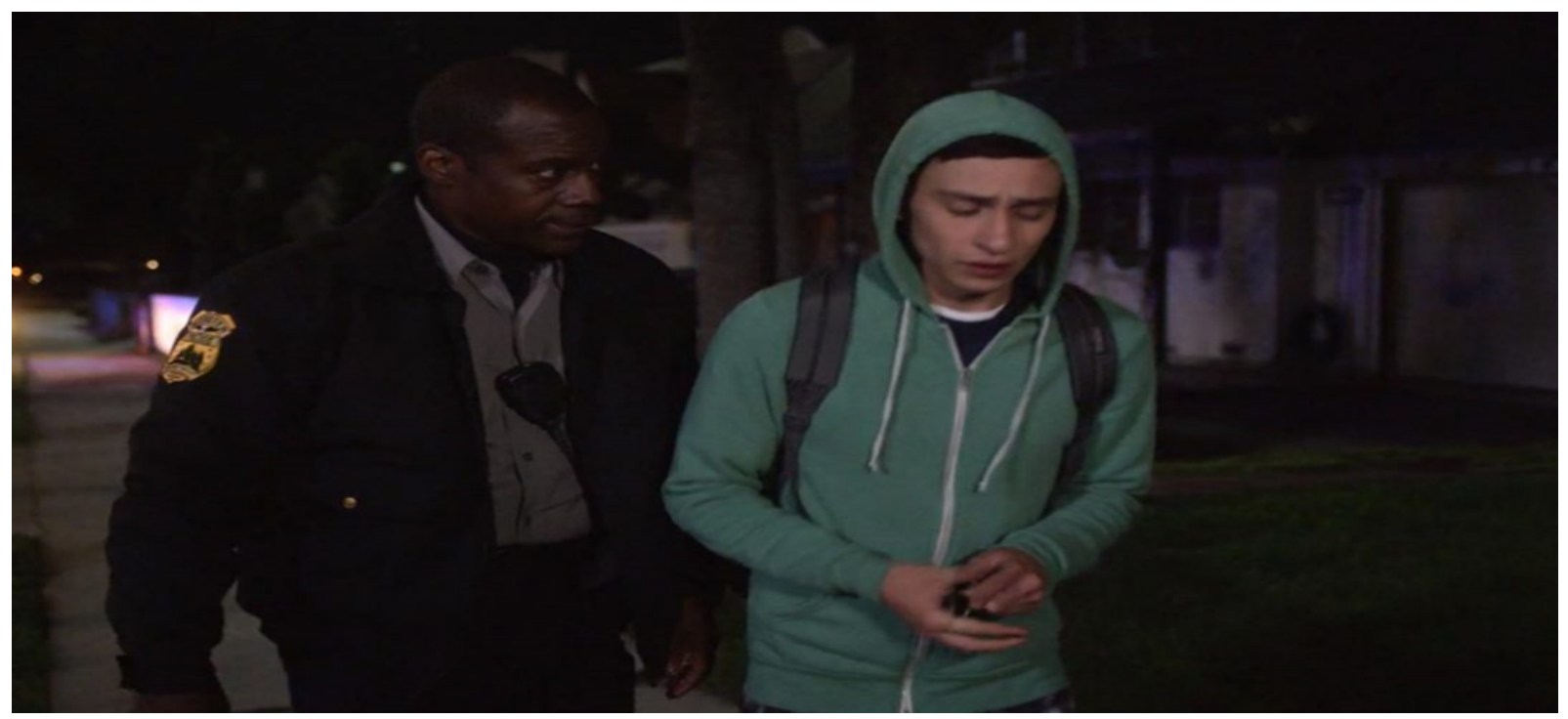

A cena anterior se refere ao episódio 6 da segunda temporada da série. Sam, na busca pela independência, procura sair de sua zona de conforto ao ir dormir na casa de seu amigo, Zahid. A experiência, apesar do apoio do amigo, acabou não saindo como o esperado, isso por que Sam, assustado com o novo ambiente, saiu tarde da noite sem ser notado pelos moradores da casa. Assustado, enquanto andava pelas ruas, Sam foi abordado por um oficial da polícia, Timms, sob suspeita de ter feito uso de substâncias ilícitas. Sam já estava um pouco tenso pela experiência que havia falhado e não conseguiu se manter parado e responder as perguntas feitas pelo oficial e continuou andando. Durante o percurso, recitava para si as quatro espécies de pinguins da Antártida e a fazer movimentos repetidos com os dedos das mãos com um elástico, na tentativa de se manter calmo. Caminhando ao lado de Sam, Timms ficou cada vez mais aborrecido pelo fato do adolescente não responder aos seus comandos, encarando como ato de desrespeito. Os dois são alcançados por Zahid que procura explicar ao oficial que Sam era um adolescente com transtorno do espectro do autismo. Sem sucesso, os dois foram conduzidos à delegacia. Essa cena é um dos muitos exemplos e críticas que a série explora: a falta de conhecimento das pessoas acerca do transtorno. É claro que a falta de informações não justifica situações tais como essa envolvendo Sam e o oficial, tampouco, o conhecimento das pessoas sobre a TEA isenta uma pessoa autista de sofrer preconceitos, discriminação e etc. Mas, a falta de informações sobre a TEA se constitui em um dos entraves para a inclusão de pessoas dentro do espectro autista na sociedade. Elas são, muitas vezes, incompreendidas, mal interpretadas, discriminadas e excluídas. A séria chama a atenção 
em diversas cenas, tais como a discutida aqui, para a necessidade de se conhecer sobre a TEA e, acima de tudo, saber como lidar com as pessoas.

No último episódio da segunda temporada, Sam toma a difícil decisão de se tornar independente. Tarefas aparentemente simples, como acordar no horário, arrumar a cama, escolher as próprias roupas, preparar o café, podem se apresentar como grandes desafios para uma pessoa no espectro. No geral, trazem uma grande carga de estresse e ansiedade. Sam, já no primeiro dia, sofre algumas frustrações, contudo, persiste, por mais assustador que todo aquele contexto se apresentasse a ele. Foi em meio à busca pela independência que decide se candidatar a uma vaga na faculdade. Após "uma saga" para escolher o curso e encontrar a universidade, consegue admissão em uma instituição que, em tese, possui estrutura adequada para pessoas autistas. Sam opta pelo curso de desenho, sua grande paixão, depois dos pinguins. Tal percurso, contudo, foi acompanhado de estresse, ansiedade, frustrações e algumas crises.

Na terceira temporada de Atypical, o telespectador pode observar que Sam começa a viver uma nova etapa de sua vida. Atypical continua focalizando na história de Sam, nas suas dificuldades, e na sua capacidade de superar os desafios de conviver em um novo ambiente - a Universidade.

Podemos pensar a terceira temporada sobre vários aspectos da trama. Assim, a série ao mesmo tempo em que mostra a rotina de um jovem autista e de sua família, aproxima o telespectador dos desafios mentais, de seus medos e dúvidas. Também vem mostrar, especialmente nesta última temporada, que apesar de todas as dificuldades, Sam tem conseguindo superar muitos desafios: Sam é um jovem que trabalha, tem uma namorada e entrou para a faculdade. Prosseguir na vida escolar é certamente um dos grandes desafios enfrentados pelas pessoas autistas, sendo que chegar à universidade é, sem dúvida, uma grande superação. Essa entrada para a universidade é o início de um novo ciclo na vida de Sam que não quer ser tratado com diferença; ele busca tomar suas próprias decisões. Sam passa pelos desafios de lidar com uma nova rotina.

Nos episódios da terceira temporada Sam também amplia seu ciclo de relacionamentos, passa por decepções e muita aprendizagens na vida social e, principalmente, de adaptação à Universidade. Para Sam, “o motivo de tantos jovens com autismo não se formarem é porque a faculdade não é para eles". Esta frase resume bem o que sente Sam e, provavelmente, muitos jovens dentro do espectro do autismo. Isto fica bastante visível nos primeiros episódios com os ritmos acelerados das aulas, por exemplo. Rev. Caminhos da Educação: diálogos, culturas e diversidades, Teresina, v. 1, n. 3, p. 95-110, set./dez. 2019 
É interessante observar que, embora Sam continue enfrentando suas limitações, nesta nova temporada, podemos perceber que ele parece mais independente e que mesmo recorrendo a outras pessoas para auxiliá-lo, o jovem se mostra mais confiante para tomar suas próprias decisões.

Outro aspecto interessante da série é que Atypical apresenta várias histórias diferentes, mas também muito próximas, pois giram em torno das mesmas questões. Casey, por exemplo, vive na série diversos dilemas, como a dificuldade inicial de adaptação à nova escola, a rejeição inicial de seus colegas e os dilemas sobre sua sexualidade; Paige, uma garota que aparentava ser bem resolvida e confiante nas duas primeiras temporadas, teve que enfrentar problemas de adaptação, sofreu bullying e deixou a universidade; $\mathrm{Na}$ terceira temporada da série, o telespectador também conhece outros distúrbios que dificultam a aprendizagem como, por exemplo, o caso de Evan (namorado de Casey) que tem dislexia, o que explica os motivos de seu "fracasso" escolar, pois ele sempre teve muitas dificuldades no processo de aprendizagem. E assim segue a trama interligando as histórias dos diversos personagens para tratar de temas muitos próximos. Atypical leva seus telespectadores a refletirem sobre vários aspectos da vida social e escolar. A série, de uma maneira leve e bem humorada, trata de assuntos delicados e convida seus telespectadores a refletirem a respeito da história dos personagens que "retratam" muitos personagens da vida real.

A série chama atenção para o papel da família, da escola e da sociedade. Neste sentido, é preciso destacar que a escola precisar estar preparada para lidar com as especificidades de seus alunos; do contrário, não será inclusiva. Entre os muitos desafios que uma pessoa autista enfrenta, e que a série aborda, se refere a pouca inserção de pessoas nessa condição, no mercado de trabalho e na universidade. Em uma das cenas da série é apresentada uma estatística em que - daqueles dentro do espectro que conseguem ingressar na universidade, em média somente um em cada cinco consegue concluir o curso. Sam, nas primeiras semanas, fica aterrorizado com a remota possibilidade de se manter no curso e concluí-lo.

A série mostra bem o início da vida de Sam na universidade, as dificuldades de adaptação à nova forma de estudo, o currículo, as aulas, etc. Neste sentido, também, é importante lembrar que Sam possui um grau leve de autismo, pertence a um a família que pode e procura lhe proporcionar diversas experiências de aprendizagem. Ele faz terapia e seus pais participam de grupos de apoio, por exemplo, o que nos leva a pensar que são Rev. Caminhos da Educação: diálogos, culturas e diversidades, Teresina, v. 1, n. 3, p. 95-110, set./dez. 2019 
muito maiores as dificuldades de muitos outros jovens que não têm as mesmas possibilidades de Sam.

A Televisão, o cinema e as séries se apresentam como uma linguagem dinâmica, pois são espaços de socialização, de educação e cultura e, feitas as devidas ressalvas, podem ser uma excelente forma de aprendizagem, devendo ser exploradas pela escola, pelos educadores e pela sociedade de modo geral. É neste sentido que Atypical traz para o seriado de TV um importante tema da vida real para ser pensado e problematizado junto com seu público.

Esse tipo de abordagem se torna cada vez mais necessário em um contexto no qual os espaços de educação e socialização estão atrelados à tecnologia da informação e comunicação. Os seriados de TV, o cinema e outras formas de mídias educativas podem ser utilizados como recursos pedagógicos da educação formal. Mas é necessário que estes recursos proporcionem a reflexão sobre sua abordagem. Neste ponto, Atypical pode ser vista como um excelente recurso didático-pedagógico para abordar a educação inclusiva na escola, pois a série nos permite observar os diferentes tipos de preconceitos, a reconhecer as diferenças, os limites, os desafios e as possibilidades presentes na trama da série.

\section{Considerações finais}

De modo geral, as diversas formas de mídia audiovisuais não vinculam apenas entretenimento. Elas também apresentam em suas tramas certa visão de mundo que podem influenciar no imaginário social, no comportamento dos indivíduos e na formação de valores morais e éticos. Essa influência pode ser analisada tanto do ponto de vista de seus aspectos positivos como negativos. Atualmente existe uma grande variedade de produções disponíveis, dentre elas podemos destacar os seriados de TV que vêm cada vez mais se popularizando entre o público. O campo da educação pode se beneficiar dessas séries para explorar sua dimensão educativa, utilizando-as como um recurso para o ensino e aprendizagens. Neste sentido, Atypical pode ser compreendida como uma série educativa e como tal pode ser aplicada no campo da educação como um recurso que, de forma dinâmica e leve, possibilita a discussão sobre diversas questões relacionada à vida de pessoas dentro do Transtorno do Espectro Autista e sua inclusão social e educacional.

\section{Referências}

Rev. Caminhos da Educação: diálogos, culturas e diversidades, Teresina, v. 1, n. 3, p. 95-110, set./dez. 2019 
ALVES, Brunna D'Luise Turato Lotti. Séries de Televisão nas aulas de Geografia: uma estratégia didática In: Congresso Internacional de Educação e Tecnologias, 2018, p. 0109.

Disponível em: http://cietenped.ufscar.br/submissao/index.php/2018/article/download/397/487/ Acesso em: 16 de jul. de 2019.

ATYPICAL, (Season 1) (Seriado). Direção: Joe Kessler, Michael Patrick, Jann Seth Gordon, Produtora: Netflix, Duração: 260 minutos, 2017.

ATYPICAL, (Season 2) (Seriado). Direção: Geeta Patel, Joe Kessler, Pete Chatmon, Ryan Csse, Silver Treen, Produtora: Netflix, 297 minutos, 2018.

ATYPICAL, (Season 3) (Seriado). Direção: Robia Rashid, Produtora: Netflix, Duração: 319 minutos, 2019.

BRAGA, Udineia Braga. O uso da mídia cinema como ferramenta de aprendizagem nas aulas de História. In: XXIX Simpósio Nacional de História: Contra os Preconceitos: História e Democracia, 2017, p. 01-12.

LOCATELLI, Aline Locatelli; MACUGLIA, Uliane. As séries de TV como ferramenta pedagógica no ensino de Química, Revista Thema, 2018, vol. 15, No 4, p. 1294- 1301. Disponível em: http://revistathema.ifsul.edu.br/index.php/thema/article/view/1086 Acesso em: 16 de jul. de 2019.

LOURO, Lopes Guacira. O cinema como pedagogia. In: LOPES, Eliana, M. Teixeira; FARIA FILHO, Luciano Mendes; VEIGA, Cynthia, Greive. 500 anos de história da educação no Brasil. Belo Horizonte: Autêntica, 2000.

MAIA FILHO, Antônio Luiz. A importância da família no cuidado da criança autista. Revista Saúde em Foco. Teresina, v. 3, n. 1, art. 1, jan./jun. 2016, p. 66-83. Disponível em:

http://www4.fsanet.com.br/revista/index.php/saudeemfoco/article/viewFile/719/1000 Acesso em: 24 de jul. de 2019.

PEREIRA, Lara Rodrigues; SILVA, Cristiani Bereta da. Como utilizar o cinema em sala de aula? Notas a respeito das prescrições para o ensino de História. ESPAÇO PEDAGÓGICO, v. 21, n. 2, Passo Fundo, jul./dez. 2014, p. 318-335.

PIMENTA, Herbene Fernandes; BARBOSA João Paulo da Silva. O autismo no ambiente familiar e a interação família escola: um estudo de caso. III Congresso Internacional de Educação Inclusiva \& III Jornada Chilena Brasileira de Educação Inclusiva e Direitos Humanos, Campina Grande - PB, 2018, p. 01-12. Disponível em: http://editorarealize.com.br/revistas/cintedi/trabalhos/TRABALHO_EV110_MD1_SA6 _ID623_11082018132007.pdf Acesso em: 24 de jul. de 2019. 
SANTA, Amanda de. O papel da escola. Folha de Londrina, 13 de fev. de 2019. Disponível em: https://www.folhadelondrina.com.br/cidades/as-dificuldades-nainclusao-da-crianca-autista-na-escola-1026606.html Acesso em: 18 de jul. de 2019.

SILVA, Alexandra Lima da; MONTI, Ednardo Monteiro Gonzaga. Viagens pelo cinema: convites à história da educação. Teresina: EDUFPI, 2019.

SKLIAR, Carlos. A inclusão que é "nossa" e a diferença que é do "outro". In: RODRIGUES, David (Org). Inclusão e educação: doze olhares sob a educação inclusiva. São Paulo: Summu, 2006.

SCHVARZMAN, Sheila. Marc Ferro, cinema, história e cinejornais: Histoire parallèle e a emergência do discurso do outro. ArtCultura, Uberlândia, v. 15, n. 26, p. 187-203, jan.jun. 2013.

SOUZA, Jéssica Itaiane R. de; LEITE, Bruno S. Utilização das Séries de TV no Ensino de Química. Rev. Virtual Quimica. |Vol 10, No. 4, 749-766. Disponível em: http://rvq.sbq.org.br/imagebank/pdf/v10n4a02.pdf Acesso em: 16 de jul. de 2019.

TENORIO, Goretti; PINHEIRO, Chloé. O que é autismo, das causas aos sinais e o tratamento. Saúde, 2 abr, 2018. Disponível em: https://saude.abril.com.br/mentesaudavel/o-que-e-autismo-das-causas-aos-sinais-e-o-tratamento/ Acesso em: 17 de jul. de 2019. 